\title{
Knowledge of Diabetes among Rural High School Children of Mandya
}

\author{
Shilpashree YD, Aliya Nusrath, Namitha Devegowda* \\ Department of Biochemistry, Adichunchanagiri Institute of Medical Sciences, India
}

Copyright $(\mathrm{C} 2018$ by authors, all rights reserved. Authors agree that this article remains permanently open access under the terms of the Creative Commons Attribution License 4.0 International License

\begin{abstract}
Background and objectives: Diabetes mellitus (DM) is one of the most commonly encountered diseases by the healthcare professionals. Knowledge about diabetes can assist in early detection and can reduce the incidence of complication. The present study aimed to evaluate the knowledge of rural school children regarding diabetes mellitus and to identify the areas of gap in the knowledge of diabetes among these children. Materials and Methods: A cross sectional questionnaire based study was conducted. Pretested questionnaire was used to assess the gap in knowledge of diabetes. The questionnaire was administered to all the high school children who consented, from the schools in and around B G Nagara. Data was tabulated and analysed using excel sheet. Results: A total of 302 students participated in the study. In this study, high school children had "General knowledge about diabetes" scores of $54.3 \%$, "Knowledge of life style and non-medical measures" scores of $50.33 \%$, "Knowledge of clinical symptoms and complications" scores of $47.35 \%$, and "Knowledge of monitoring and treatment of diabetes" scores of $22.18 \%$. Conclusion: The high school children in this study had fair awareness of diabetes in certain aspects, even though there were many gaps in other areas of knowledge. The awareness of high school children about the disease can be of great help to reduce the risk of developing diabetes and its related complications in future.
\end{abstract}

Keywords Diabetes, Awareness, Rural, High School Children

\section{Introduction}

Diabetes mellitus (DM) is one of the most commonly encountered diseases by the healthcare professional. ${ }^{1}$ The prevalence of diabetes for all the age groups worldwide was $2.8 \%$ in 2000 and estimated to rise to $4.4 \%$ in $2030{ }^{2}$ According to the data reported from International Diabetes Federation, around 366 million people currently diagnosed to have diabetes, $80 \%$ of them live in low and middle-income countries. ${ }^{3}$

India leads the world and is labeled as world diabetic capital. The number of people with diabetes in India is currently around 40.9 million and is expected to rise to 69.9 million by 2025 as reported in Diabetes Atlas 2006, published by the International Diabetes Federation. ${ }^{4}$

Several factors has been attributed to the rising prevalence of diabetes including urbanisation, following western lifestyle, reduced physical activity and excess calorie intake. ${ }^{5}$ The complication associated with diabetes like cardiovascular diseases, nephropathy, neuropathy and retinopathy has been known to increase the mortality and morbidity. 6 This will have significant impact on the financial status and quality of life of the patient.

Several studies conducted across the world suggest that there is a lack of awareness and knowledge among the public regarding various aspects of diabetes. ${ }^{7,8}$ Knowledge about diabetes can assist in early detection and can reduce the incidence of complication.

The data regarding the status of awareness and knowledge of school children about diabetes is very important to plan the public health programs. Hence, we took the present study to evaluate the knowledge and awareness of high school children about diabetes and to identify the areas of weakness in the knowledge among these children regarding diabetes.

The data generated from this study would give an idea to the policy makers and the government regarding gap in the knowledge of diabetes, which should be addressed. The awareness about diabetes among this study age group would help in reducing the risk of development of diabetes and its complications.

\section{Materials and Methods}

A cross -sectional survey was conducted among the high school students studying in and around BG Nagara, Mandya district. Institutional ethical committee approval was taken before commencing the study. Students who were willing to participate were instructed about the survey 
before answering the questions. Pre tested questionnaire was used to assess the knowledge about diabetes. The questionnaire focused on various aspects of diabetes mellitus, namely general knowledge about diabetes, risk factors, symptoms, complications, treatment, lifestyle, and non-medical measures.

Only those students who were willing to participate in the study were included. The students absent on the day of questionnaire administration were excluded from the study. Purpose of the study was explained and all difficult terms were explained in local language. The questionnaire was distributed to all the high school students and was asked to be filled anonymously. Twenty minutes time was given to complete the questionnaire.

\section{Statistical Analysis}

Statistical analyses were performed using Microsoft excel. Data are presented as number (\%) for categorical variables and mean (standard deviation) for continuous variables.

\section{Results}

Of the 325 number of students approached, a total of 302 students participated in study giving a response rate of
$92.92 \%$. The age of the study population ranged from 12 to $18 \mathrm{yrs}$ with mean age of the study population as $14 \pm 1 \mathrm{yr}$. Out of 302 study subjects 192 were male participants and 109 were female participants. Participant's response regarding knowledge about diabetes is shown in Figure 1. Regarding knowledge of diabetes, about 232 students had good knowledge about lack of insulin causes diabetes (71.52\%), 218 participants perceived that if untreated can lead to rise in blood sugar (67.22\%) and 176 students knew that there are different types of DM (54.3\%). However 245,152 and 137 students believed that eating too much sugar causes diabetes $(81.12 \%)$, diabetes is caused due to problem of excretion of sugar $(47.01 \%)$ and is a hereditary condition $(42.15 \%)$ respectively.

Figure 2 shows response of the study population regarding life style and non-medical measures about diabetes. Out of 325 students, 187 felt that diabetics should eat low caloric and protein rich diet (55.96\%), 180 of the study population felt that there is a delay healing of wound (55.29\%), 202 felt diabetics should be careful when clipping nails (62.25\%) and 164 felt jackfruit and mangoes were not good for diabetics(50.33\%). However, there were misconceptions too. Forty six students (14.23\%) felt preparing food is more important than its nature, $115(35.43 \%)$ felt diabetic diet consists of special types of food and 104(32.11\%) felt stockings are not bad for diabetics.

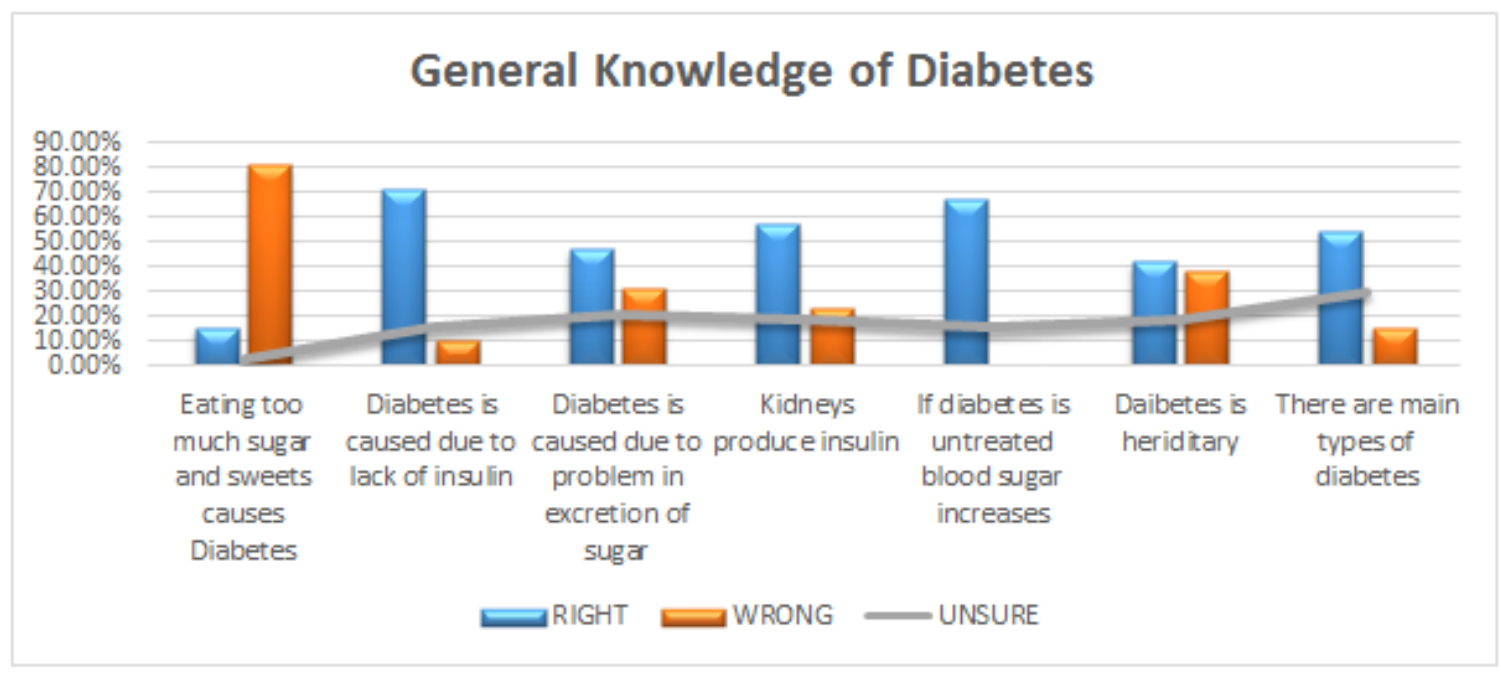

Figure 1. General Knowledge of Diabetes 


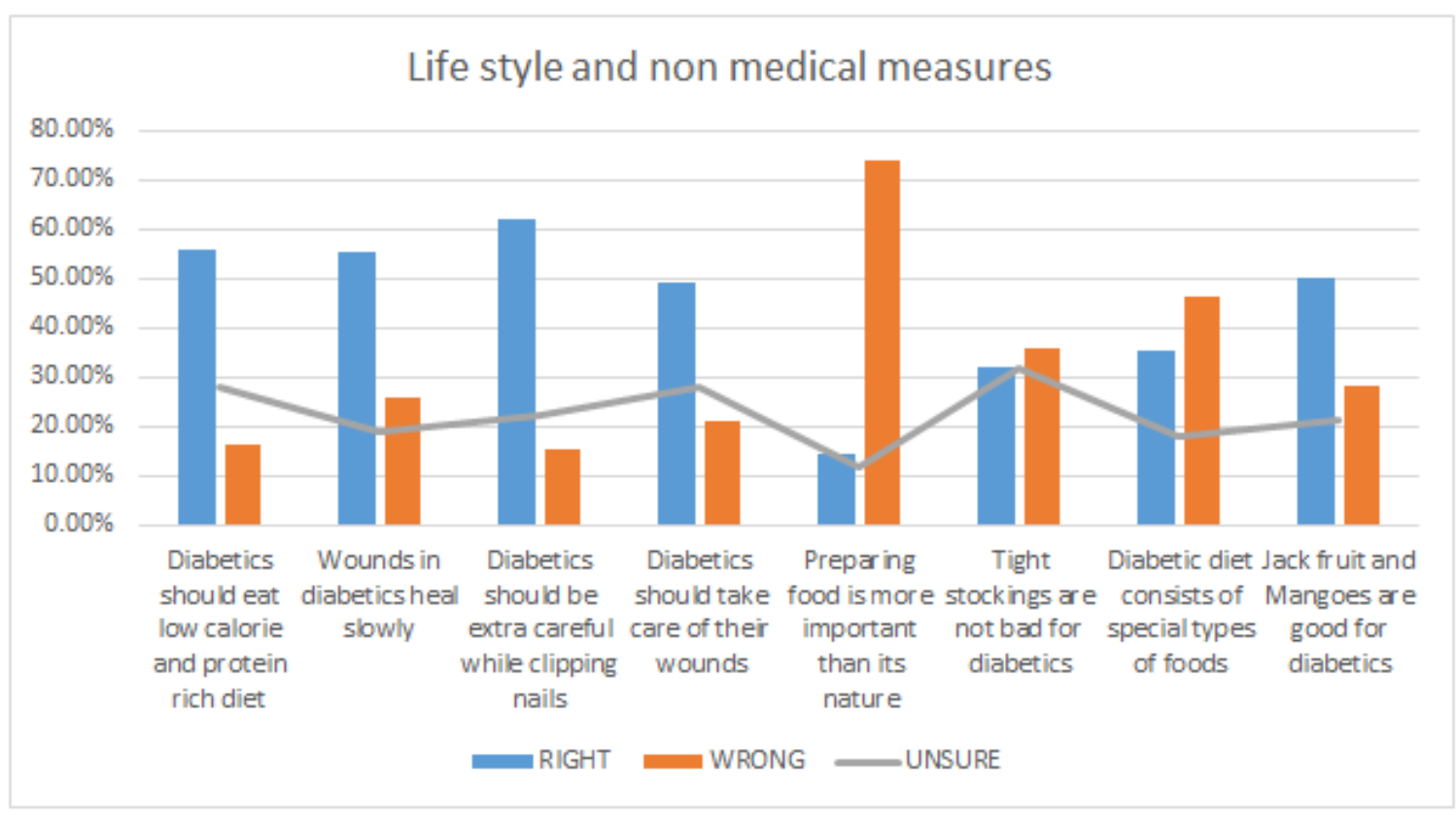

Figure 2. Life style and non-medical measures

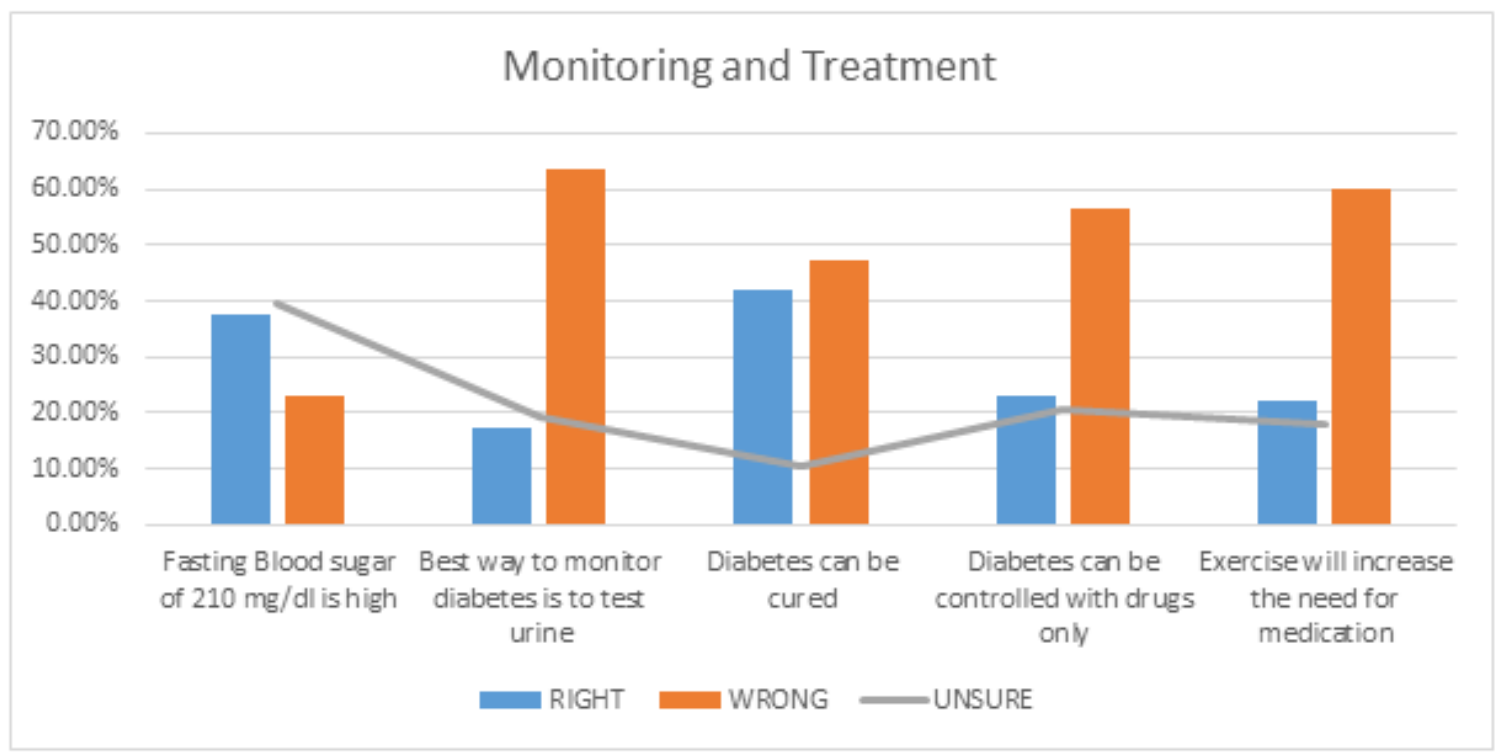

Figure 3. Response regarding monitoring and treatment of diabetes

Figure 3 shows response regarding monitoring and treatment of diabetes. On monitoring and treatment of diabetes the participants had least knowledge and less than $50 \%$ gave right answers on questions regarding diabetes can be cured $137(42.05 \%)$, diabetes can be controlled by drugs $73(22.84 \%)$, exercise will increase the need for medication $72(22.18 \%)$ and fasting blood sugar of 210 $\mathrm{mg} / \mathrm{dl}$ is high $122(37.41 \%)$.

Approximately half the students had correct knowledge regarding clinical features and complications with 199 students $(61.25 \%)$ answering correctly on high blood sugar increases thirst and urination and 154 participants had least knowledge on diabetes can cause loss of feeling in hands and feet $(47.35 \%)$ in this section as shown in Table 1.

Table 1. Participants' response regarding clinical feature and complication about diabetes

\begin{tabular}{|c|c|c|c|}
\hline & RIGHT & WRONG & UNSURE \\
\hline $\begin{array}{c}\text { High blood sugar causes } \\
\text { shaking and sweating }\end{array}$ & $50 \%$ & $27.15 \%$ & $22.84 \%$ \\
\hline $\begin{array}{c}\text { High blood sugar causes } \\
\text { increased thirst and } \\
\text { urination }\end{array}$ & $61.25 \%$ & $17.88 \%$ & $20.86 \%$ \\
\hline $\begin{array}{c}\text { Diabetes causes poor } \\
\text { circulation }\end{array}$ & $49 \%$ & $24.50 \%$ & $26.50 \%$ \\
\hline $\begin{array}{c}\text { Diabetes can damage } \\
\text { kidneys }\end{array}$ & $51.60 \%$ & $26.50 \%$ & $21.90 \%$ \\
\hline $\begin{array}{c}\text { Diabetes can cause loss of } \\
\text { feeling in hands and feet }\end{array}$ & $47.35 \%$ & $28.14 \%$ & $24.50 \%$ \\
\hline
\end{tabular}




\section{Discussion}

The data of our study provides a snapshot of knowledge and awareness of high school children about diabetes. Knowledge about diabetes can assist in early detection of the disease and reduce the incidence of its complications. This can be achieved by improving the knowledge of general population about diabetes. In this study, the participants had a fair knowledge, although there were large gaps in many domains in the knowledge of diabetes.

In the present study, awareness of the study population regarding general knowledge, life style and non-medical measures, clinical symptoms and complication, monitoring and treatment among high school children were $54.3 \%$, $50.33 \%, 47.35 \%$ and $22.18 \%$ respectively. In the survey conducted by Hussini et al, the study population had comparatively good knowledge on all aspects of diabetes compared to this study. ${ }^{9}$ The comparatively poor knowledge can be attributed to lower status and quality education among the family members in rural India. Further, studies among adult population also have reported poor knowledge regarding prevention of diabetes, role of obesity and physical inactivity as risk factors of diabetes, complications of diabetes etc. ${ }^{7,8}$

There is a general myth that diabetes occurs due to high consumption of sugars. In the present study $81.5 \%$ believed that diabetes occurs due to high consumption of sugars which is much higher compared to other south Indian studies. $^{7,10}$ This may be due misconceptions and lack of knowledge of the elders of the rural society and probably due to misguiding of community health workers because of their poor knowledge. In the current study, the high school children had a poor knowledge about monitoring and treatment of diabetes.

Almost $60 \%$ under the misconception that exercise increases the need for medication and $56.62 \%$ believing diabetes can be cured with drugs only. As exercise and lifestyle modifications play a vital role in prevention of diabetes and its complications, this poor knowledge increases the risk of complications in the community, which already has dearth of health care facilities. Hence, steps must be taken to promote physical activity and change societal perception of health-by-health care planners. $^{7}$

Early diagnosis can prevent or delay the complications of diabetes. In this study the awareness of symptoms and complications of diabetes was moderate similar to a study from coastal Karnataka but other south Indian studies showed poor knowledge of complications of diabetes with the study from Chennai reporting only $19 \%$ of participant being aware of the complications and a study from Kolar reporting $75 \%$ of non-diabetic having no knowledge of diabetic complications. ${ }^{7,8,10}$ This higher awareness in this study could be due to rising prevalence of diabetes in rural areas with probably family members of these children suffering from diabetes or its complication and hence having personal knowledge from direct exposure.

The present research reports are inadequate on knowledge of the rural high schoolchildren about diabetes. Considering the high prevalence of diabetes in India and rising incidence of diabetes in rural population due to socio economic growth, it is highly recommended to elaborate knowledge about diabetes at young age. ${ }^{11}$ The awareness of high school students about disease can be of great help to reduce the risk of developing diabetes and its related complications in future.

In the current study population, many may never get into higher education and some may not even pre university education, hence chances of them gaining knowledge about diabetes are limited. Hence, an attempt must be made to educate the young ones in their high school age. Students must be encouraged to contribute in different activities related to diabetes such as doing seminars, presenting posters or projects. World diabetes day maybe celebrated in all schools to increase awareness about diabetes among the young ones.

The ministry of education and health can work in tandem to achieve success in creating awareness among young ones and protecting their health.

The study had few limitations low sample size, family history of diabetes and its correlation with the level of knowledge was not assessed.

\section{Conclusions}

The present research shows the knowledge gap of the rural high school children about diabetes. Awareness of schoolchildren about the disease can be of great help to reduce the risk of developing diabetes and its related complications in future.

\section{REFERENCES}

[1] Ginter E, Simko V. Global prevalence and future of diabetes mellitus. Adv Exp Med Biol 2012; 771:35-41.

[2] Sarah I, Bchir, Gojka R G, Green A, Sicree R, King H .Global Prevalence of Diabetes Estimates for the year 2000 and projections for 2030. Diabetes Care 2004;27(5):1047-53

[3] Unwin N, Whiting D, Guariguata L, Ghyoot G, Gan D, editors. Diabetes Atlas. $5^{\text {th }}$ ed. Brussels, Belgium: International Diabetes Federation; 2011. International Diabetes Federation; pp. 11-74.

[4] Mohan V, Sandeep S, Deepa R, Shah B, Varghese C. Epidemiology of type 2 diabetes: Indian scenario. Indian $\mathrm{J}$ Med Res 2007;125:217-30

[5] Unadike BC, Chineye S. Knowledge, awareness and impact of diabetes among adolescents in Uyo, Nigeria. African journal of diabetes medicine 2009; 3:12-14. 
[6] Ryder B. Screening for diabetic retinopathy. BMJ 1995;311:207-8

[7] Mohan D, Raj D, Shanthirani CS, Datta M, Unwin NC, Kapur A, Mohan V Awareness and Knowledge of Diabetes in Chennai - The Chennai Urban Rural Epidemiology Study [CURES - 9]. J Assoc Physicians India 2005; 53:283-287.

[8] Muninarayana C, Balachandra G, Hiremath SG, Iyengar K, Anil NS. Prevalence and awareness regarding diabetes mellitus in rural Tamaka, Kolar. Int J Diabetes Dev Ctries 2010; 30(1):18-21.

[9] Hussaini AL, Mustafa Adolescents knowledge and awareness of diabetes

mellitus in Kuwait. Alexandria Journal of Medicine 2016; 52: $61-66$

[10] Holla R, Prabhu S, Shetty S, Deshpande S, Balla KS, Hegde $S$ et al. Awareness about diabetes among adolescents of Mangalore, south India. NUJHS2014; 4(2):118-20

[11] Ramachandran A1, Snehalatha C, Baskar AD, Mary S, Kumar CK, Selvam S, Catherine S, Vijay V. Temporal changes in prevalence of diabetes and impaired glucose tolerance associated with lifestyle transition occurring in the rural population in India Diabetologia 2004;47(5):860-5 